\title{
Efficient Experimental Approach to Evaluate Mass Transfer Limitations for Monolithic DOCs
}

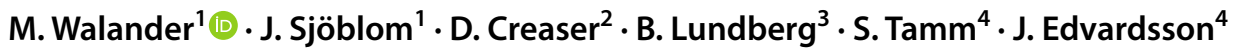

Published online: 12 December 2018

(c) The Author(s) 2018

\begin{abstract}
The diesel oxidation catalyst (DOC, $\mathrm{Pt} / \gamma-\mathrm{Al}_{2} \mathrm{O}_{3}$ ) was used in a synthetic-gas catalyst test bench to study internal mass transfer limitations during $\mathrm{NO}$ oxidation. A simple and fast experimental methodology, by varying the washcoat thickness in monolithic DOCs was developed and the results were evaluated using various experimental time scales. The ratio between the reaction time constant and the washcoat diffusion time constant was useful in identifying temperatures where the DOCs tested transitioned between a kinetically controlled region and an internal mass transfer controlled region. The NO conversion was shown to be significantly limited by internal mass transfer already at $175^{\circ} \mathrm{C}$ for an average washcoat thickness of $110 \mu \mathrm{m}$.
\end{abstract}

Keywords Diesel oxidation catalyst $\cdot$ Catalytic washcoat $\cdot$ Internal mass transfer limitation $\cdot$ Time constant $\cdot$ NO oxidation

\section{Introduction}

As a consequence of using internal combustion engines, there is need for removal of inherently produced emissions due to their harmful effect on the environment and human health [1]. For diesel engines, the diesel oxidation catalyst (DOC) is a vital part of the exhaust aftertreatment system (EATS) since its performance very much affects the downstream components' performance. Hence, gaining insight into the DOC operation is of utmost interest [2]. For efficient heterogeneous catalyst design, large active surface area is key. This is usually achieved through dispersion of the active material in a support material with high inner specific surface area [3]. However, the support material hinders mass transfer due to the structure of the pores $[4,5]$. Hence, there is a tradeoff between good dispersion of the active material

M. Walander

magwal@chalmers.se

$\triangle$ J. Sjöblom

jonas.sjoblom@chalmers.se

1 Mechanics and Maritime Sciences, Chalmers University of Technology, 41296 Gothenburg, Sweden

2 Chemistry and Chemical Engineering, Chalmers University of Technology, 41296 Gothenburg, Sweden

3 Volvo Car Corporation, 41878 Gothenburg, Sweden

4 Johnson Matthey, 42131 Gothenburg, Sweden while still maintaining good transport properties through the support material. There are several methods for evaluating internal mass transfer; e.g. the Prater-Weisz modulus, Thiele modulus and comparisons between various experimental time constants $[3,6]$. The various methods all have one common denominator-to some extent they compare the mass transfer process with the reaction process, be it in terms of the rate constant, observed reaction rates and estimates of effective diffusivity or their corresponding time constants. The diffusivity within the porous material is often approximated with the parallel pore model $[7,8]$ while the reaction rate can be evaluated using experimentally observed values [6].

One problem is that the observed reaction rate itself often includes mass transport phenomena and therefore the reaction rate is underestimated. In this work we propose a simple and fast experimental methodology for evaluating mass transfer limitations; through comparing two DOCs with different washcoat thickness but the same amount of noble metal (per reactor volume), along with time scales to evaluate the experimental data. Instead of using the observed reaction rate for each catalyst, the DOC with thin washcoat is used to evaluate the reaction time constant since it is less likely to suffer from internal mass transfer limitations. The experimental procedure is based on short $\mathrm{NO}$ concentration steps to avoid a potential change in noble metal oxidation state, which could vastly change reaction kinetics, since the likelihood of a change in noble metal oxidation state increases with reaction time [9]. 


\section{Materials and Methods}

The DOC was used to study internal mass transfer limitations during concentration step experiments using two $1 \times 1$ inch cylindrical cordierite monoliths with different amounts of washcoat ( $2.6 \mathrm{~g} / \mathrm{in}^{3}$ and $1.3 \mathrm{~g} / \mathrm{in}^{3}$ of $\gamma$-alumina), however constant platinum loading ( $15 \mathrm{~g} / \mathrm{ft}^{3}$ monolith)—i.e. same amount of noble metal in each monolith. Each DOC was subject to concentration steps using a synthetic-gas catalyst test bench (SCAT) provided by Johnson Matthey. The step; a 20-100 ppm NO step during $60 \mathrm{~s}$, was injected into a steady flow of nitrogen ( $30 \mathrm{l} / \mathrm{min}$ at STP) with a constant oxygen level of $8 \%$. The step was repeated three times to obtain a standard deviation and then each set of steps was performed at different DOC operating temperatures. The procedure was repeated for both increasing and decreasing temperature order to identify the possible effects of changes in the noble metal oxidation state.

The properties of the DOCs used in the experiments are summarized in Table 1. The average washcoat thickness is calculated assuming that the washcoat forms a perfect slab, thus neglecting monolith corner effects. Both custom-made model DOCs, containing only platinum noble metal on $\gamma$-alumina, were provided by Johnson Matthey.

The SCAT consists of an electrically heated oven where the carrier gas flows in two-pass configuration around the DOC itself to ensure a nearly adiabatic reactor operation. The reactants are injected $200 \mathrm{~mm}$ upstream of the DOC, where the inlet temperature and pressure are measured, to minimize axial dispersion and therefore maintaining the ideal step created by the mass flow controller. The inlet and outlet concentrations are measured using a FTIR analyser.

To analyse the experimental data presented in the Sect. 3, mass transfer and reaction time constants [8] are used to compare how the thick and thin washcoat experiments differ. The residence time is calculated as:

$t_{\text {resd }}=\frac{l}{v}$

where $l$ is the channel length in $(\mathrm{m})$ and $v$ is the mean channel gas velocity in $(\mathrm{m} / \mathrm{s})$. The time constant for transverse diffusion is:

$t_{t d}=\frac{R_{\text {bulk }}^{2}}{D_{A}}$ where $D_{A}$ is the is the free molecular diffusivity in $\left(\mathrm{m}^{2} / \mathrm{s}\right)$ and $R_{\text {bulk }}$ is the effective transverse diffusion length in (m), calculated as:

$R_{b u l k}=\frac{A_{b u l k}}{P}$

where $A_{b u l k}$ is the open channel cross-sectional area in $\left(\mathrm{m}^{2}\right)$ and $P$ is the perimeter of the washcoat in $(\mathrm{m})$. Quite similarly, the time constant for washcoat diffusion is calculated as:

$t_{w s c}=\frac{R_{w s c}^{2}}{D_{e f f}}$

where $D_{\text {eff }}$ is the effective washcoat diffusivity in $\left(\mathrm{m}^{2} / \mathrm{s}\right)$ and $R_{w s c}$ is the effective washcoat thickness in (m), calculated as:

$R_{w s c}=\frac{A_{w s c}}{P}$

where $A_{w s c}$ is the cross-sectional area of the washcoat in $\left(\mathrm{m}^{2}\right)$. The effective diffusivity is, as one alternative, calculated using the parallel pore model [7]:

$D_{\text {eff }}=\frac{\varepsilon / \tau}{\left(\frac{1}{D_{A}}+\frac{1}{D_{k n}}\right)}$

where $\varepsilon$ is the washcoat porosity, $\tau$ is the tortuosity of the washcoat and $D_{k n}$ is the Knudsen diffusivity in $\left(\mathrm{m}^{2} / \mathrm{s}\right)$, which is calculated as:

$D_{k n}=\frac{d_{p}}{3} \sqrt{\frac{8 R T_{i n}}{\pi M}}$

where $d_{p}$ is the pore average diameter of mesopores in the washcoat in (m), $R$ is the gas constant, $T_{i n}$ is the inlet temperature in $(\mathrm{K})$ and $M$ is the molar mass in $(\mathrm{g} / \mathrm{mol})$. Lastly, the time scale for reaction is calculated as the inverse of the estimated reaction rate constant for an assumed first order reaction:

$t_{r}=\frac{1}{k_{i}}$

where $k_{i}$ is the first order reaction rate constant in $\left(\mathrm{s}^{-1}\right)$ for each temperature, calculated from the experiments with thin washcoat since it is less likely to be limited by internal mass
Table 1 Properties of Pt-based DOCs

\begin{tabular}{lllllll}
\hline Referenced as (-) & $\begin{array}{l}\text { Pt-loading (g/ } \\
\mathrm{ft}^{3} \text { monolith) }\end{array}$ & $\begin{array}{l}\text { Washcoat } \\
\text { loading }(\mathrm{g} / \\
\left.\mathrm{in}^{3}\right)\end{array}$ & $\begin{array}{l}\text { Washcoat } \\
\text { thickness } \\
(\mu \mathrm{m})\end{array}$ & $\begin{array}{l}\text { Cell } \\
\text { density } \\
(\mathrm{CPSI})\end{array}$ & $\begin{array}{l}\text { Wall thick- Dispersion (\%) } \\
\text { ness }(\mathrm{mm})\end{array}$ & \\
\hline "Thick" & 15 & 2.6 & 110 & 400 & 0.152 & $23.9 \pm 0.3$ \\
"Thin" & 15 & 1.3 & 55 & 400 & 0.152 & $24.2 \pm 0.9$ \\
\hline
\end{tabular}


transfer. For all calculated conversions, for the catalyst with thin washcoat, a first order plug flow mole balance is fitted to the experimental data points from which the reaction rate constant can be calculated for a range of temperatures:

$X_{N O}=1-e^{\left(-k \cdot t_{\text {resd }}\right)}$

\section{Results and Discussion}

A representative step response is shown Fig. 1.

The $60 \mathrm{~s}$ long, 20-100 ppm NO feed step starts at $\mathrm{t}=0 \mathrm{~s}$. However, the step response does not appear until around $\mathrm{t}=10 \mathrm{~s}$ due to time lag in the mass flow controllers and dispersion effects within the analyzer and piping before and after the reactor itself. Furthermore, the step shape differs from an ideal step due to dispersion effects as well as possible kinetic or mass transfer effects. However, the transient nature of the experiments is not considered in this work, instead the last $30 \mathrm{~s}$ of the high signal is used to calculate a steady state conversion for all performed experiments. The steady state conversion, with associated standard deviation for each data point, is shown in Fig. 2.

Firstly, it can be seen that the error bars are relatively small in comparison to the difference between conversion for thick and thin washcoat, hence the difference between the two DOCs is not due to experimental "noise". The additional experiments with thick washcoat with decreasing temperature between each experiment (red data points) agree very well with the initial experiments (solid line). On the other hand, the same analysis for thin washcoat reveals that for the additional experiments (blue data points), after exposing the DOC to high temperatures, there is a difference in conversion-possibly due to a change in oxidation state of Pt. However, despite minor differences in conversion due to different oxidation state of the noble metal during up and down temperature ramps, there is a clear and consistent difference in conversion between the thick and thin washcoat. One key difference comes from the fact that when the washcoat thickness is changed, so does the open channel area and thus the residence time differ by roughly $25 \%$ between thick and thin washcoat. One simple way of accounting for the change in conversion due to a difference in residence time is to use Eq. 9. The rate constant is found through fitting the equation to the experiments with thin washcoat and its long residence time. Once the rate constant is found, the shorter residence time of the thick washcoat can be used to recalculate the conversion for thin washcoat (black dotdashed line in Fig. 2). Once the thin washcoat conversion is adjusted with the lower residence time, it can be seen that there is no longer a significant difference in conversion at $175^{\circ} \mathrm{C}$, compared to the estimated experimental deviations. However, there is still an appreciable difference in conversion at higher temperatures, and since the difference in washcoat diffusion length differs by a factor of 2, it is likely that the reaction for the DOC with thick washcoat is limited by internal mass transfer.

The difference in conversion for DOCs with thick and thin washcoat seen in Fig. 2 can be explained using the time constants, presented in Sect. 2, which are shown in Fig. 3.

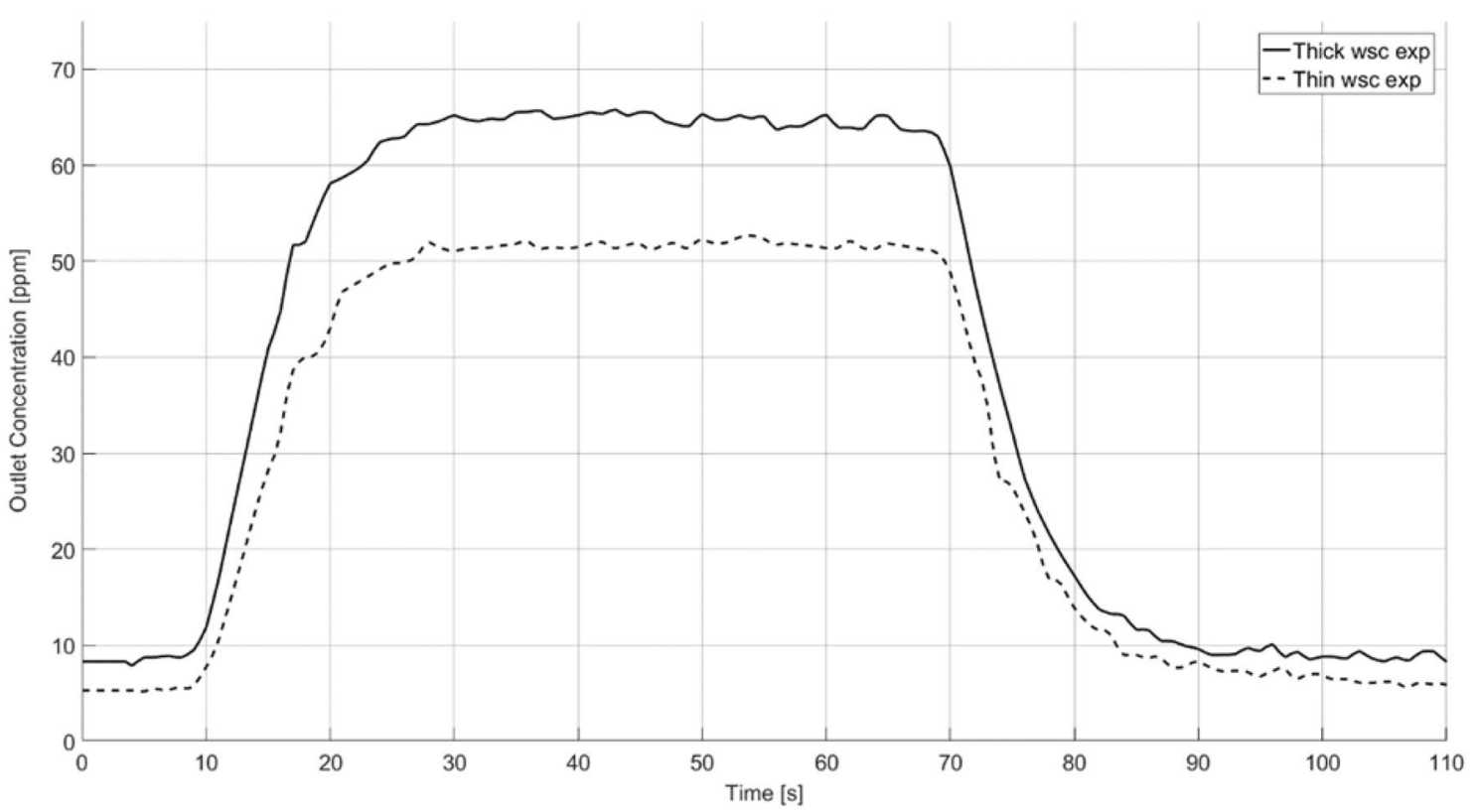

Fig. 1 Step response for $20-100 \mathrm{ppm}$ NO step at $241{ }^{\circ} \mathrm{C}$. The solid and dashed line corresponds to the DOC with thick and thin washcoat, respectively 


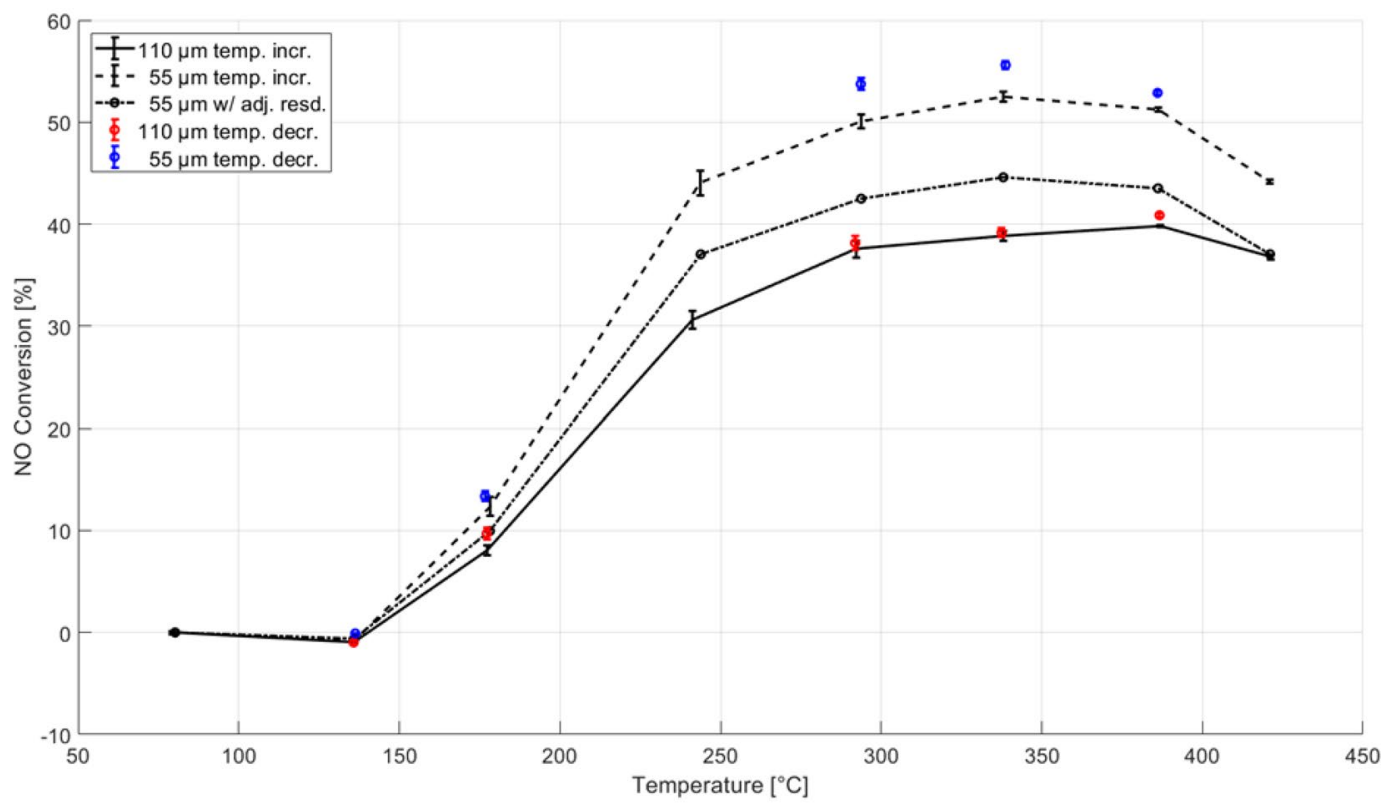

Fig. 2 Steady state conversion for thick (solid black line) and thin (dotted black line) washcoat for increasing temperature. The red and blue data points correspond to additional experiments performed with decreasing temperature. Error bars are calculated based on standard deviation for each data point. The black dot-dashed line corresponds to a case where the reaction rate constants for thin washcoat and residence time for thick washcoat are used to estimate the variation in conversion due to a variation in residence time

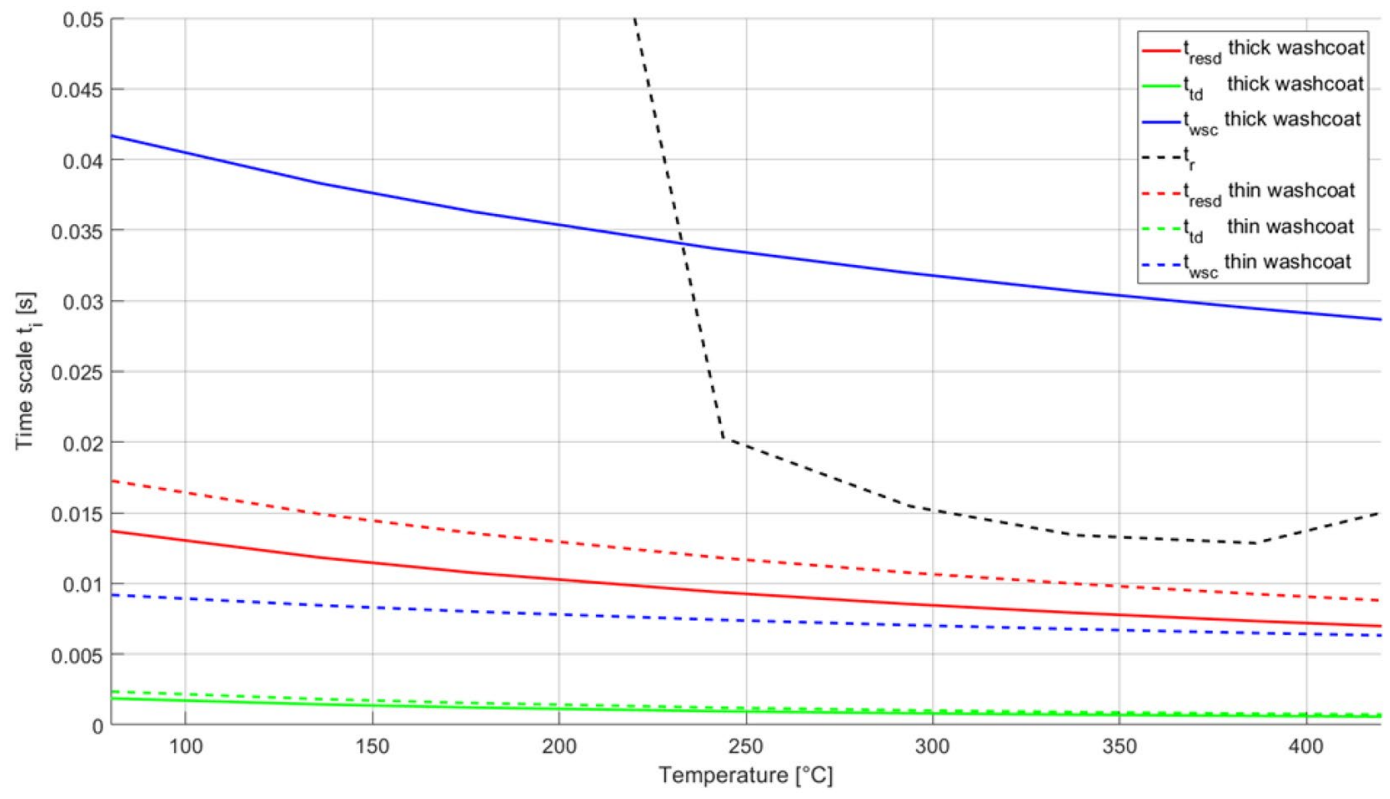

Fig. 3 Residence time, time constants for transverse diffusion, washcoat diffusion and reaction for thick (solid line) and thin washcoat (dotted line). Note that the reaction time constant is only shown for

As mentioned, two geometric parameters change when the washcoat thickness is changed; the cross-sectional areas of the washcoat and the open channel as well as the washcoat perimeter. Since the open channel area is larger when thin washcoat, but it should be identical for thick washcoat. The effective diffusivity for the washcoat diffusion time constant is calculated using the parallel pore model with $\tau=4$ and $\varepsilon=0.85$

the washcoat is thin, the mean gas velocity is lower and as a result the residence time is higher for the DOC with thin washcoat. If the conversion for thin washcoat is adjusted as explained above, there must be some other phenomenon that 
is responsible for the additional difference in conversion. The time constants for transverse diffusion are similar since variation in open channel area is counteracted by the change in perimeter-hence the effective transverse diffusion length scale is basically the same for thick and thin washcoat. It can also be seen that the transverse diffusion is by far the fastest step and should therefore not limit conversion.

At the lowest experimental temperature where NO conversion could be detected, reaction is by far the slowest step-hence by analyzing this graph alone it could be argued that at $175^{\circ} \mathrm{C}$ both DOCs are kinetically controlled. At $240{ }^{\circ} \mathrm{C}$ the reaction time constant has drastically lowered and is clearly not the slowest step anymore. Here the time constant for washcoat diffusion for the thick washcoat is the slowest step and is therefore likely a limiting factor.

To be able to distinguish the importance of reaction time and washcoat diffusion time, a ratio between these two is presented in Fig. 4.

Florén et al. [10] defined that for any of the above mentioned processes to be limiting, its timescale should be an order of magnitude larger than the others compared. This is used to define the kinetically controlled region in Fig. 4. We further define that for values below one the washcoat diffusion is the limiting factor and in between these extremes there is a mixed region where both processes are of comparable importance. By examining Fig. 4, it can be seen that below around $200^{\circ} \mathrm{C}$, the DOC with thin washcoat is entirely kinetically controlled. As temperature increases, the thin washcoat rapidly enters the mixed region where it stays until the reaction is limited by the NO equilibrium above $400{ }^{\circ} \mathrm{C}$. The DOC with thick washcoat is somewhat limited by internal mass transfer already at $175{ }^{\circ} \mathrm{C}$ and at around $230{ }^{\circ} \mathrm{C}$ it enters the internal mass transfer controlled region. The difference between thin and thick washcoat at higher temperatures is roughly a factor of 4 which corresponds to the difference in washcoat resistance, $R_{w s c}$.

\section{Conclusion}

Lab scale diesel oxidation catalysts were used to study internal mass transfer limitations in a SCAT test bench. A simple and fast experimental methodology along with a simple way to account for variations in residence time were able to provide experimental data that, in combination with experimental time constants, could be used to evaluate internal mass transfer limitations. It was found that the DOC with thin washcoat was initially kinetically controlled at the lower temperatures, while the performance of both DOCs was limited by internal mass transfer to various degrees at higher temperatures. Experimentally, it was shown that NO oxidation can begin to be internally mass transfer limited at as low as $175^{\circ} \mathrm{C}$ for an average washcoat thickness of $110 \mu \mathrm{m}$. One drawback with the simplistic experimental methodology was the resulting difference in residence time. However, this was addressed by performing analysis of time constants.

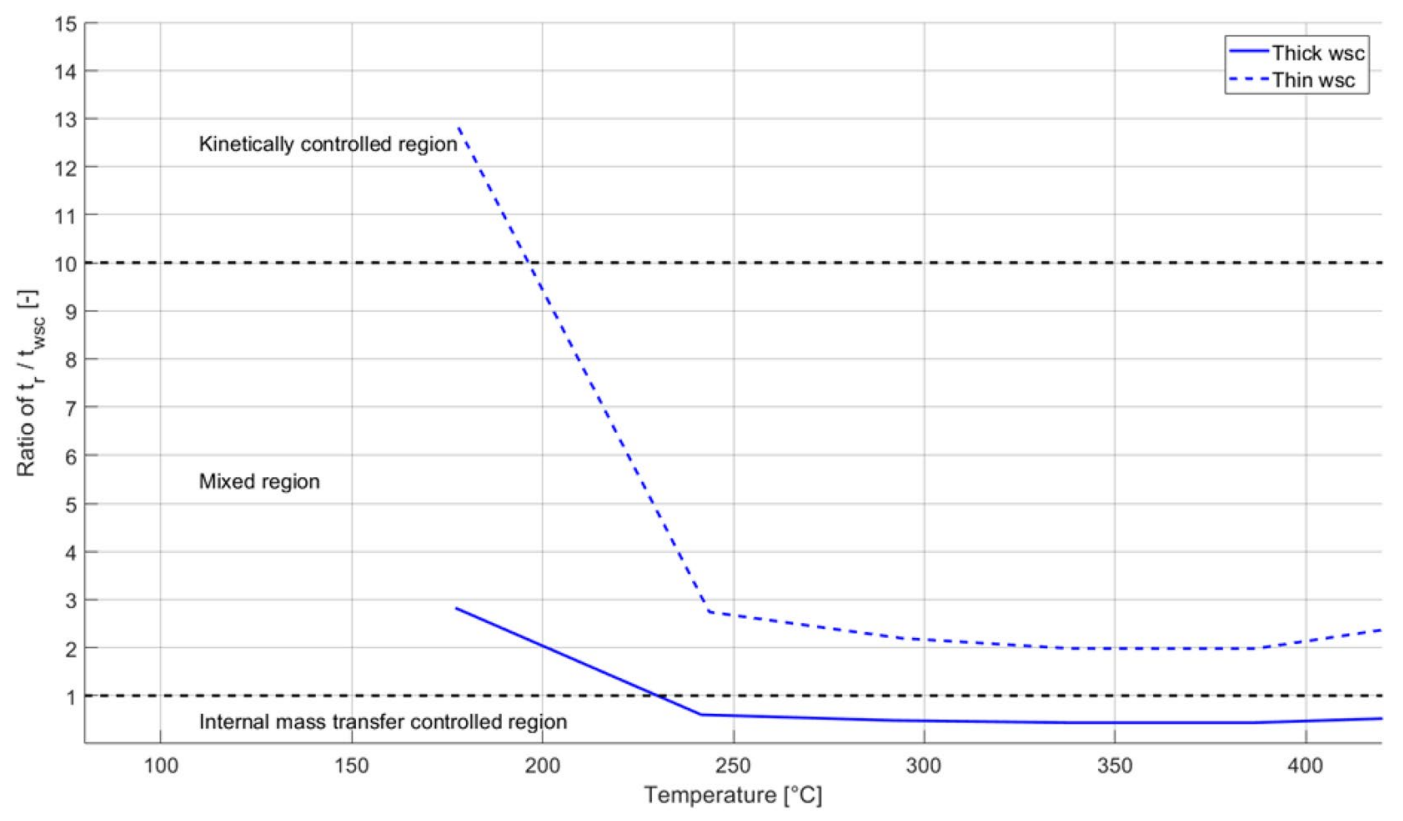

Fig. 4 Ratio of reaction time constant to washcoat diffusion time constant. Blue solid and dotted line correspond to thick and thin washcoat, respectively. Three control regions; kinetically controlled, mixed and internal mass transfer controlled region has been defined where values ten and one correspond to boundary values between these regions 
Acknowledgements All project members along with the technical support at Johnson Matthey are deeply acknowledged for their help with performing and analyzing the experiments. The Swedish Energy Agency (FFI Project 42814-1) is acknowledged for financial support.

Open Access This article is distributed under the terms of the Creative Commons Attribution 4.0 International License (http://creativeco mmons.org/licenses/by/4.0/), which permits unrestricted use, distribution, and reproduction in any medium, provided you give appropriate credit to the original author(s) and the source, provide a link to the Creative Commons license, and indicate if changes were made.

\section{References}

1. Webster DE (2001) 25 years of catalytic automotive pollution control: a collaborative effort. Top Catal 1617:1-4

2. Lundberg B, Sjöblom J, Johansson $\AA$, Westerberg B, Creaser D (2016) DOC modeling combining kinetics and mass transfer using inert washcoat layers. Appl Catal B 191:116-129

3. Beller M, Renken A, van Santen RA (2012) Catalysis: from principles to applications. Wiley-VCH, Weinheim, pp 85-90)
4. Man Baek S, Ho Kang J, Lee K-J, Hyun Nam J (2014) A numerical study of the effectiveness factors of nickel catalyst pellets used in steam methane reforming for residential fuel cell applications. Int J Hydrog Energy 39:9180-9192

5. Nabgan B, Abdullah TAT, Tahir M, Nabgan W, Gambo Y, Ibrahim M, Saeh I, Moghadamian K (2017) Evaluation of theoretical and experimental mass transfer limitation in steamreforming of phenol-PET waste to hydrogen production over Ni/La-promoted $\mathrm{Al}_{2} \mathrm{O}_{3}$ catalyst. J Environ Chem Eng 5:2752-2760

6. Metkar PS, Balakotaiah V, Harold MP (2012) Experimental and kinetic modeling study of $\mathrm{NO}$ oxidation: comparison of $\mathrm{Fe}$ and Cu-zeolite catalysts. Catal Today 184(1):115-128

7. Wheeler A (1951) Adv Catal 3:239

8. Metkar PS, Balakotaiah V, Harold MP (2011) Experimental study of mass transfer limitations in $\mathrm{Fe}$ - and $\mathrm{Cu}$-zeolite-based $\mathrm{NH}_{3}$-SCR monolithic catalysts. Chem Eng Sci 66(21):5192-5203

9. Russell A, Epling WS (2011) Diesel oxidation catalysts. Catal Rev Sci Eng 53(4):337-423

10. Florén C-R, Van den Bossche M, Creaser D, Grönbeck H, Carlsson P-A, Korpi H, Skoglundh M (2018) Catal Sci Technol $8: 508-520$ 